Provided for non-commercial research and education use. Not for reproduction, distribution or commercial use.

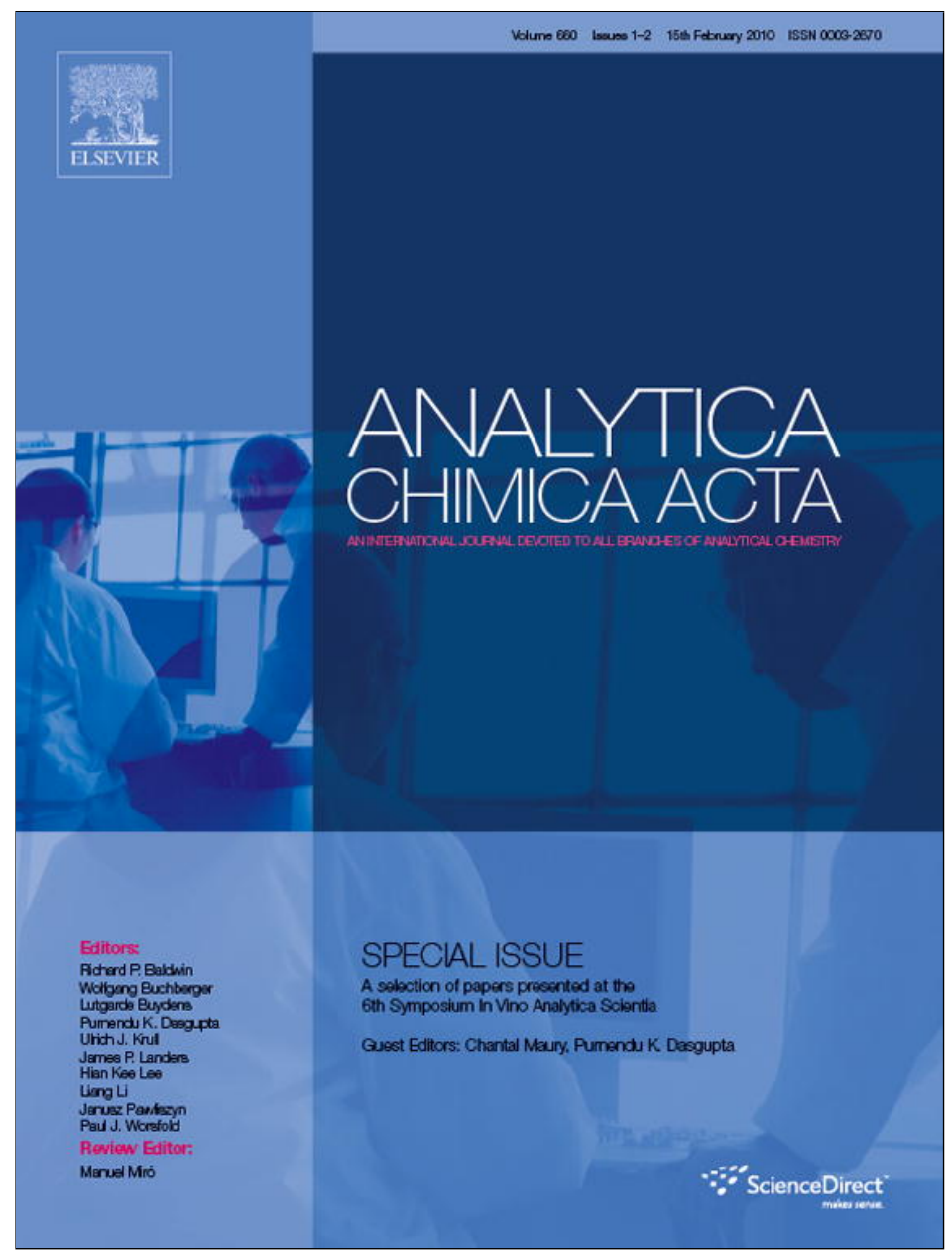

This article appeared in a journal published by Elsevier. The attached copy is furnished to the author for internal non-commercial research and education use, including for instruction at the authors institution and sharing with colleagues.

Other uses, including reproduction and distribution, or selling or licensing copies, or posting to personal, institutional or third party websites are prohibited.

In most cases authors are permitted to post their version of the article (e.g. in Word or Tex form) to their personal website or institutional repository. Authors requiring further information regarding Elsevier's archiving and manuscript policies are encouraged to visit:

http://www.elsevier.com/copyright 


\title{
Statistical correlation between flavanolic composition, colour and sensorial parameters in grape seed during ripening
}

\author{
Raúl Ferrer-Gallego, Matilde García-Marino, José Miguel Hernández-Hierro, Julián C. Rivas-Gonzalo, \\ M. Teresa Escribano-Bailón* \\ Grupo de Investigación en Polifenoles, Unidad de Nutrición y Bromatología, Facultad de Farmacia, Universidad de Salamanca, Campus Miguel de Unamuno, E 37007 Salamanca, Spain
}

\section{A R T I C L E I N F O}

\section{Article history:}

Received 29 July 2009

Received in revised form

22 September 2009

Accepted 26 September 2009

Available online 1 October 2009

\section{Keywords:}

Astringency

Tannic intensity

Proanthocyanidins

Ripening

Grape seeds

\begin{abstract}
A B S T R A C T
The aim of this work has been to determine the correlations between sensory analysis, colour and content of main flavanols present in seeds. For this, the flavanic composition of grape seeds with different degrees of maturity was analysed by HPLC-DAD-MS and the obtained results were correlated with CIELab colour parameters, perceived colour (C), hardness of the seed (HS), tannic intensity (TI) and astringency (A). Multiple linear regression analysis (MLR) with the variables showing significant correlations $(p<0.05)$ was also performed. Grape seeds undergo important decreases in the content of catechins and procyanidin oligomers during ripening. Epicatechin-(4-8)-epicatechin-3-O-gallate (B2G) and (-)-epicatechin-3-Ogallate (ECG) are the flavanolic compounds whose contents decrease most. The changes in the phenolic composition accompany changes in TI, A and HS. The total content of flavanols in the seed is not the only factor affecting these attributes, since samples containing higher contents in flavanols can exhibit less astringency and tannic intensity than others with lower ones. The qualitative profile of the seeds is, therefore, also responsible for the sensations elicited in the mouth. A and HS parameters are more affected by the presence of galloylated dimeric procyanidins in the molecule than TI. CIELab colour parameters of seeds have high correlation coefficients with many flavanolic compounds. ECG was the compound most related to these parameters.
\end{abstract}

(c) 2009 Elsevier B.V. All rights reserved.

\section{Introduction}

Qualitative and quantitative phenolic composition of grapes depends on multiple factors, including climate, variety, soil, and degree of ripeness [1-3], the phenolic maturity of grapes being decisive for the production of quality red wines. During the first period of berry growth, phenolic compounds are accumulated [4,5] while a softening and a colouring of the berry characterise the second period or fruit ripening [6,7]. Changes occurring in the berries during maturation can also be observed in the seeds [8]. It is commonly accepted that during grape maturation, the seeds undergo modifications in their phenolic composition [9-11] affecting the sensations perceived in the mouth. Moreover, changes in seed coat colour have been related to developmental changes in berry anthocyanins and total skin phenolics indicating that the external appearance and colour of the seed may be used as an additional indicator of overall berry ripeness [8].

Among the phenolic compounds, the catechins and the proanthocyanidins contribute directly to the astringency and, indirectly,

\footnotetext{
* Corresponding author. Tel.: +34 923294 537; fax: +34 923294515.

E-mail address: escriban@usal.es (M. Teresa Escribano-Bailón).
}

through the interaction with anthocyanins, to the colour of red wines. In the berry, these compounds are mainly located in skin and seeds from which they are extracted to the wine. Although seeds represent only $0-6 \%$ of berry weight, they are an important source of flavanols for wines [12]. Grape seed composition is characterised by the presence of catechins and procyanidins which are composed of $(+)$-catechin, (-)-epicatechin and (-)-epicatechin-3-O-gallate units. Among the oligomers, dimers are usually the most abundant compounds, the dimer B2 being the major component in seeds [7,13-21]. Trimers C1 (epicatechin- $(4 \beta \rightarrow 8)$-epicatechin- $(4 \beta \rightarrow 8)$-epicatechin) and EEC (epicatechin- $(4 \beta \rightarrow 8)$-epicatechin- $(4 \beta \rightarrow 8)$-catechin) are also well represented $[7,14,22]$. Another characteristic of the flavanol composition of grape seeds is that galloylation always appears to occur on an epicatechin unit; no compound with catechin-0-gallate has been found $[14,15,20]$.

It has been accepted that astringency is not a taste, but a tactile sensation [23-26] that results from the interaction with proteins, causing a loss in the lubricating power of saliva, or with the glycoproteins of the mouth epithelium [27]. The affinity of polyphenols for proteins depends on the number of phenolic moieties [28]. Interaction between polyphenols and proteins increases with the degree of polymerisation and the number of galloyl units in the 
polyphenol structure [29-33], but it is not necessarily related to astringency as conformational changes in the protein structure provoked by the interaction with the polyphenol also seem to be implicated [34]. Different authors have indicated that extractable flavan 3-ol monomers and low molecular weight seed procyanidins decrease during fruit ripening $[9,11,35]$, which might affect the astringency of the seeds.

Several methods have been developed in order to obtain an objective evaluation of the astringency [36-41], but most of the methods are indirect, which makes it difficult to draw conclusions. For that reason sensory analysis continues to be a useful tool [42-44].

The aim of this work has been to determine the correlations between sensory analysis, colour and content of main flavanols present in seeds and to determine which flavanolic compounds or family of flavanolic compounds better explain the variations occurring within these parameters. With this objective, the flavanic composition of grape seeds with different degrees of maturity was analysed by HPLC-DAD-MS and the obtained results were correlated with CIELab colour parameters, perceived colour (C), hardness of the seed (HS), tannic intensity (TI) and astringency (A). Multiple linear regression analysis (MLR) with the variables showing significant correlations $(p<0.05)$ was also performed.

\section{Materials and methods}

\subsection{Samples}

Vitis vinifera L. cv. "Graciano” red grapes were collected in 2008 at eight different developmental stages: from veraison (September 3rd) until over-ripeness (November 5th). Also, in order to compare the features of the seeds picked in different years at technological maturity, samples were collected at harvest in 2005-2008. The sampling was carried out as follows: 300 berries were collected from both sides of vines located in different rows within the vineyard. Edge rows and the first two vines in a row were avoided. Berries were collected from the top, middle and bottom of the cluster and were immediately frozen and stored at $-20^{\circ} \mathrm{C}$ until analyses were performed.

\subsection{Extraction}

Extraction was carried out as described in García-Marino et al. [45]. Grape seeds were separated manually and freeze-dried. Samples were ground to obtain a homogeneous powder for extraction. The grape seed powder was extracted with 75\% methanol (Merck, LiChrosolv $^{\circledR}$, Darmstadt, Germany). The methanolic extracts were concentrated at low pressure until an aqueous extract was obtained. The extracts were injected directly into the chromatographic system after filtration through a $0.45 \mu \mathrm{m}$ filter. All analyses were performed in triplicate.

\subsection{HPLC-DAD-MS analysis}

HPLC-DAD-MS analysis was carried out as described in GarcíaMarino et al. [45]. LC-diode array detection (DAD) analysis was performed in a Hewlett-Packard 1200 series liquid chromatograph, and detection was carried out using a photodiode detector. A Spherisorb ${ }^{\circledR}$ S3 ODS- 2 reverse phase $3 \mu \mathrm{m}$ particle size $\mathrm{C} 18$ column $150 \mathrm{~mm} \times 4.6 \mathrm{~mm}$ i.d. (Waters, Ireland) thermostatted at $25^{\circ} \mathrm{C}$ was used.

The solvents used were: (A) $2.5 \%$ acetic acid, (B) $2.5 \%$ acetic acid/acetonitrile (90:10, v:v), and (C) HPLC-grade acetonitrile, establishing the following gradient: from 0 to $100 \%$ B for $5 \mathrm{~min}$, from 0 to $15 \% \mathrm{C}$ for $25 \mathrm{~min}$, from 15 to $50 \% \mathrm{C}$ for $5 \mathrm{~min}$, and isocratic
$50 \% \mathrm{C}$ for $5 \mathrm{~min}$ at a flow rate of $0.5 \mathrm{~mL} \mathrm{~min}^{-1}$. Detection was carried out at $280 \mathrm{~nm}$ as the preferred wavelength.

The mass analyses were performed using a FinniganTM LCQ ion trap detector (Thermoquest, San Jose, CA, USA) equipped with an API source, using an electrospray ionisation (ESI) interface. The LC system was connected to the probe of the mass spectrometer via the UV cell outlet. Both sheath gas and auxiliary gas were nitrogen and helium. The sheath gas flow was $1.2 \mathrm{~L} \mathrm{~min}^{-1}$ and the auxiliary gas flow, $6 \mathrm{~L} \mathrm{~min}^{-1}$. The source voltage and the capillary voltage used were $4.50 \mathrm{kV}$ and $28 \mathrm{~V}$, respectively, and the capillary temperature $270^{\circ} \mathrm{C}$. Spectra were recorded in positive ion mode between $\mathrm{m} / \mathrm{z}$ 120 and 2000. The mass spectrometer was programmed to do a series of two consecutive scans: a full mass, and an $\mathrm{MS}^{2}$ scan of the most abundant ion in the full mass, using a normalised energy of collision of $45 \%$.

Quantification was performed by HPLC/DAD using calibration curves of $(+)$-catechin, purchased from Sigma and of procyanidins obtained in our laboratory as described in González-Manzano et al. [46].

\subsection{Statistical treatment}

Significant differences were determined by one-way analysis of variance (ANOVA) using the SPSS Program, Version 13.0 for Windows software package (SPSS, Inc., Chicago, IL). Correlations and multiple linear regression (MLR) were performed using the same SPSS program. The parameters $R$ (multiple correlation coefficient), $B$ (non-standardised regression coefficients) and $\beta$ (standardised regression coefficients) were obtained.

\subsection{Colour analysis}

The colour of the seeds was determined by means of a Minolta colorimeter CR-300 (Osaka, Japan) and recorded in $L^{*} a^{*} b^{*}$ colour system. The $L^{*} a^{*} b^{*}$ colour system consists of a lightness component $\left(L^{*}\right)$ and two chromatic components: the $a^{*}$ value represents green $(-a)$ to red $(+a)$ while the $b^{*}$ value represents blue $(-b)$ to yellow $(+b)$ colours. Values of hue angle $\left(h_{a b}\right)$ and chroma $\left(C_{a b}^{*}\right)$ obtained from $a^{*}$ and $b^{*}$ parameters were also given by the instrument. The colorimeter was calibrated using a standard white plate $\left(L^{*}=97.10\right.$, $a^{*}=+0.13, b^{*}=+1.88, C_{a b}^{*}=1.88$ and $\left.h_{a b}=86.1\right)$.

\subsection{Sensory analysis}

Sensory characteristics of the seeds were analysed in terms of hardness of the seed (HS), tannic intensity (TI) and astringency (A) according to the norms of "l'Institut Coopératif du Vin" [42]. These characteristics were evaluated by a trained panel of 11 oenologists with experience in taste tests.

\section{Results and discussion}

\subsection{Sensory characteristics of grapes}

In order to determine the consistency of the trained panel, oneway ANOVA was done with the scores given by them. As can be seen in Table 1 the variation between different kinds of seeds (between groups) is always higher than the discrepancy between the values assigned by each of the panellists for the same seed sample (within groups), which allows us to confirm the reliability of the sensory panel.

Fig. 1 shows the scores given to the seeds at different stages of ripeness for the attributes of colour, HS, TI and A. The colour corresponding to the first sampling is noticeably lower than that of the other samples, but the panellists hardly distinguish between the 
Table 1

Results of the one-way ANOVA performed with the scores given by the panellists.

\begin{tabular}{llrlll}
\hline & Sum of squares & df & Mean square & $F$ & Sig. \\
\hline Colour & & 7 & 1.688 & 7.411 & 0.000 \\
Between groups & 11.818 & 58 & 0.228 & & \\
Within groups & 13.213 & 65 & & & \\
Total & 25.030 & & & & \\
& & 7 & 2.952 & 5.574 & 0.000 \\
Hardness of the seed & & 59 & 0.530 & & \\
Between groups & 20.664 & 66 & & & \\
Within groups & 31.246 & & & & \\
Total & 51.910 & & & & \\
Tannic intensity & & 7 & 1.923 & 4.986 & 0.000 \\
Between groups & 13.462 & 57 & 0.386 & & \\
Within groups & 21.984 & 64 & & & \\
Total & 35.446 & & & & \\
Astringenc & & 7 & 1.865 & 4.210 & 0.001 \\
Between groups & 13.058 & 55 & 0.443 & & \\
Within groups & 24.371 & 62 & & & \\
Total & 37.429 & & & & \\
\hline
\end{tabular}

Between groups: variation between different kinds of seeds. Within groups: variation between the values assigned by each panellist for the same seed sample.

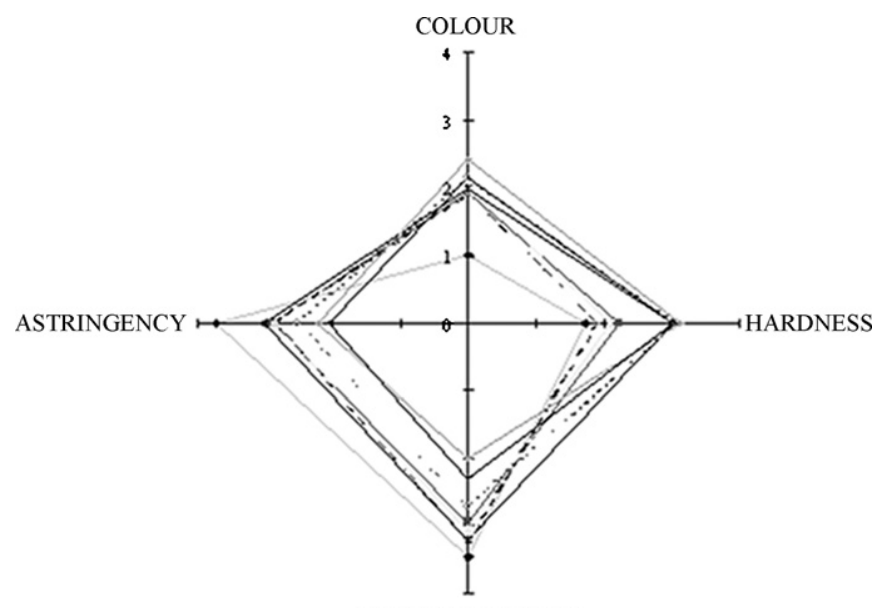

TANNIC INTENSITY

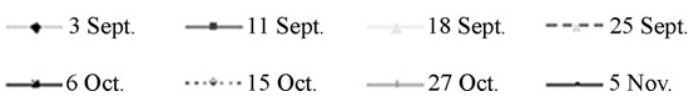

Fig. 1. Scores given to the seeds from grapes picked at different stages of ripeness for the attributes of colour, hardness of the seed, tannic intensity and astringency.

colours of the samples in the other ripeness stages. This proves that the visual evaluation of the seed colour provides poor information about the degree of ripeness of the seed.

Regarding TI and A attributes, at veraison (September 3rd), the seeds achieve the highest scores which tend to diminish as the degree of maturity increases. HS shows a contrary trend. When seeds are easily smashed, the dryness and asperity felt in the lips and palate are reduced.

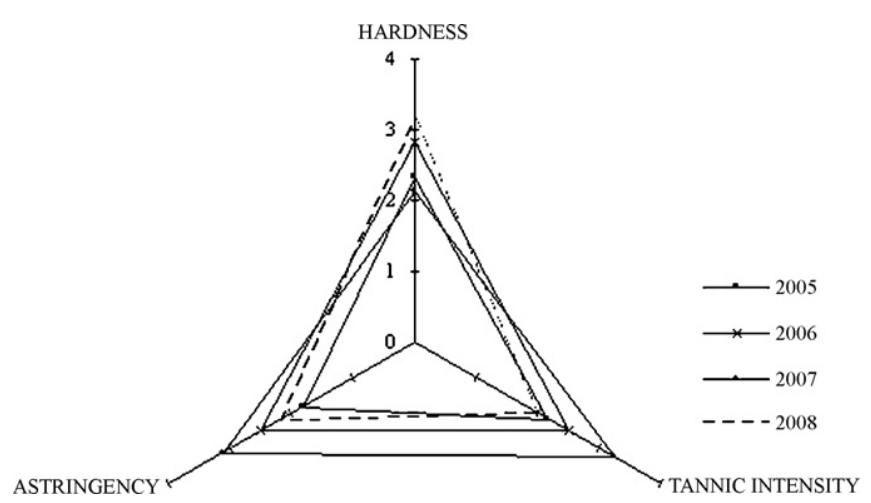

Fig. 2. Scores given to the seeds from grapes picked at harvest in 2005-2008 for the attributes of colour, hardness of the seed, tannic intensity and astringency.

Table 3

Total content of flavanols in the seed extracts obtained from grapes collected at harvest during the years 2005-2008.

\begin{tabular}{lllll}
\hline & 2005 & 2006 & 2007 & 2008 \\
& Mean \pm S.D. & Mean \pm S.D. & Mean \pm S.D. & Mean \pm S.D. \\
\hline Total $\left(\mathrm{mg} \mathrm{g}^{-1}\right)$ & $40.90 \pm 2.90^{c}$ & $25.25 \pm 4.05^{\mathrm{a}}$ & $35.37 \pm 1.79^{\mathrm{bc}}$ & $30.75 \pm 0.46^{\mathrm{ab}}$ \\
\hline
\end{tabular}

S.D. = standard deviation $(n=3)$. Different lower case letters indicate significant $(p<0.05)$ differences between samples.

Fig. 2 shows the results of the sensory analysis carried out on seeds from grapes picked at maturity over four consecutive harvest seasons (2005-2008). As in the previous assay the direct relationship between $\mathrm{TI}$ and $\mathrm{A}$ and indirect relationship between these two attributes and HS can be observed. Based on the panellists' scores achieved by the samples and in their own perceptions integrating all sensations perceived in mouth, the panel determined that better phenolic maturity was reached in 2005 and 2008 than in 2006 and 2007.

\subsection{Composition analysis of grapes}

Tables 2 and 3 show the total contents of flavanols in the seed extracts obtained from grapes at different stages of maturity and those from grapes collected at harvest over several years (2005-2008). There is an important decrease in the flavanol contents during ripeness, less than half the total quantity at veraison remaining at the end of the sampling. This decrease is probably related to the decrease observed in the sensory attributes astringency and tannic intensity and to the increase in hardness. Nevertheless, the total content of flavanols in the seed is not the only factor affecting these attributes. Samples from 2006 have the lowest quantity in total flavanols, but had higher scores in A and TI than those from 2005 or 2008 . Therefore, the qualitative profile of the seeds could also be responsible for the sensations elicited in the mouth.

The main catechins and proanthocyanidins present in the chromatograms of seed extracts were quantified. These correspond to the three flavan-3-ol monomers: (+)-catechin, (-)-epicatechin and (-)-epicatechin 3-0-gallate and to proanthocyanidins up to a degree of polymerisation of four. The degree of polymerisation

Table 2

Total content of flavanols in the seed extracts obtained from grapes at different maturity stages.

\begin{tabular}{|c|c|c|c|c|c|c|c|c|}
\hline & \multicolumn{8}{|l|}{2008} \\
\hline & $\begin{array}{l}03 \text { September } \\
\text { Mean } \pm \text { S.D. }\end{array}$ & $\begin{array}{l}11 \text { September } \\
\text { Mean } \pm \text { S.D. }\end{array}$ & $\begin{array}{l}18 \text { September } \\
\text { Mean } \pm \text { S.D. }\end{array}$ & $\begin{array}{l}25 \text { September } \\
\text { Mean } \pm \text { S.D. }\end{array}$ & $\begin{array}{l}06 \text { October } \\
\text { Mean } \pm \text { S.D. }\end{array}$ & $\begin{array}{l}15 \text { October } \\
\text { Mean } \pm \text { S.D. }\end{array}$ & $\begin{array}{l}27 \text { October } \\
\text { Mean } \pm \text { S.D. }\end{array}$ & $\begin{array}{l}05 \text { November } \\
\text { Mean } \pm \text { S.D. }\end{array}$ \\
\hline Total (mg g $\left.{ }^{-1}\right)$ & $74.33 \pm 3.67^{d}$ & $70.50 \pm 6.66^{\mathrm{cd}}$ & $64.38 \pm 1.33^{c}$ & $51.80 \pm 2.43^{b}$ & $45.64 \pm 1.17^{b}$ & $33.04 \pm 1.40^{\mathrm{a}}$ & $30.75 \pm 0.46^{\mathrm{a}}$ & $32.96 \pm 5.16^{a}$ \\
\hline
\end{tabular}

S.D. $=$ standard deviation $(n=3)$. Different lower case letters, a, b, c, d, indicate significant $(p<0.05)$ differences between samples. 


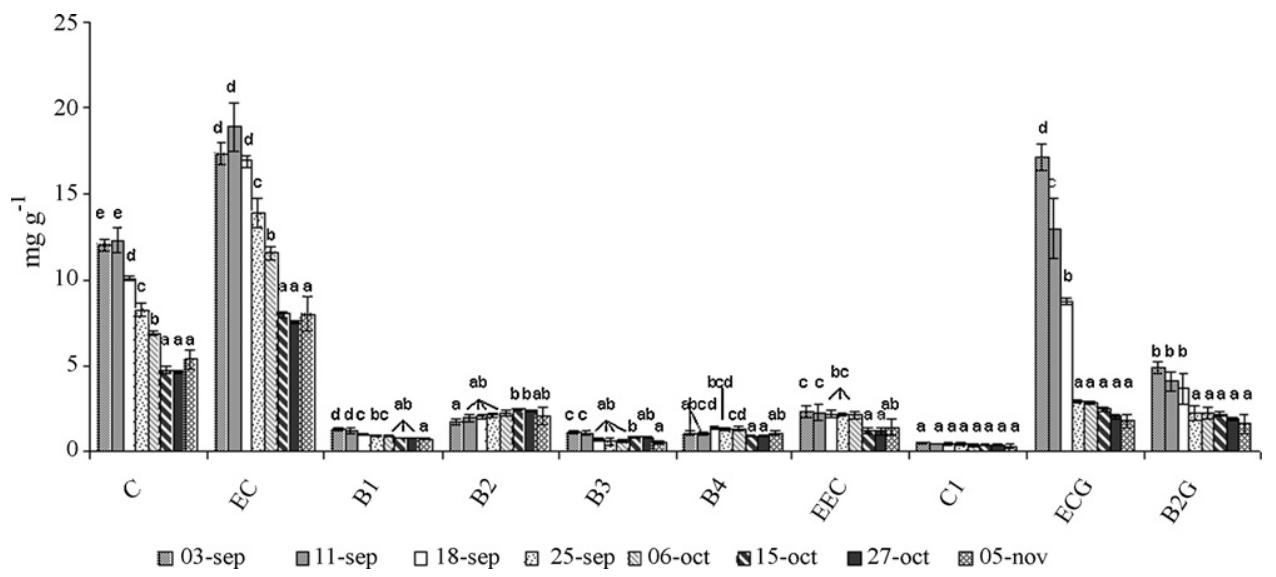

Fig. 3. Content of the main catechins and proanthocyanidins present in the chromatograms of the seed extracts. S.D. $=$ standard deviation ( $n=3$ ). Different lower case letters, a, b, c, indicate significant $(p<0.05)$ differences in the content of the compound, between samples collected at different degrees of ripening. Abbreviations are the same as in Table 5 .

of each procyanidin could be obtained from the MS analysis and the complete identification of the most abundant ones was established by comparison of their chromatographic and spectrometric features with those from standards previously obtained in our laboratory $[47,48]$.

During maturation there is a fall in the concentration of most of the identified flavanols (Fig. 3). Monomers and galloylated compounds undergo the sharpest drop. Among them epicatechin-(48)-epicatechin-3-O-gallate (B2G) and (-)-epicatechin-3-O-gallate (ECG) stand out because of their decrease of $60 \%$ and $86 \%$, respectively. It is known that the galloylation increases the procyanidin's ability to precipitate salivary proteins [37]. For this reason it is possible that a decrease in these compounds could have important consequences on the astringency and/or the tannic intensity. Near maturity no significant differences in the flavanolic composition of the seeds were obtained. It seems, therefore, that on October 15th the plant reaches its highest phenolic maturity (probably due to climatic conditions) and that it could not improve even if the fruit remained for a few days more on the vine.

Larger molecular weight procyanidins have been reported in grape seeds than those studied in our work and that must certainly be the case [27]. As it is accepted that proanthocyanidin astringency increases with chain length up to the decamer level [49], a decrease in the content of these proanthocyanidins can be expected as astringency decreases during the ripening process. The disappearance of these high molecular weight procyanidins, which were not detected in our extracts, does not give rise to lower molecular weight procyanidins, like those studied herein, since only a slight insignificant increase in the content of the procyanidin $\mathrm{B} 2$ can be observed.

Peleg et al. [50] indicated that astringency increases with an increase in the molecular size from monomers to trimers. Samples corresponding to 2006 and 2007, which were scored as more astringent, tend to present lower relative percentages of monomers and higher ones of dimers and trimers than 2005 and 2008. Even though the differences in some cases were not significant (Table 4).

\subsection{Colorimetric analysis}

During grape growing the colour of the seeds changes from an initial green, typical of the unripe grapes, to a dark brown at harvest, which could be related to oxidative processes $[4,12]$. This change could only be noticed by the panel at very early stages of maturity (Fig. 1). Colour parameters obtained by the colorimeter are shown in Figs. 4 and 5. During maturity, a decrease in $b^{*}$ parameter and an increase in $a^{*}$ could be observed (Fig. 4). This can be interpreted as a

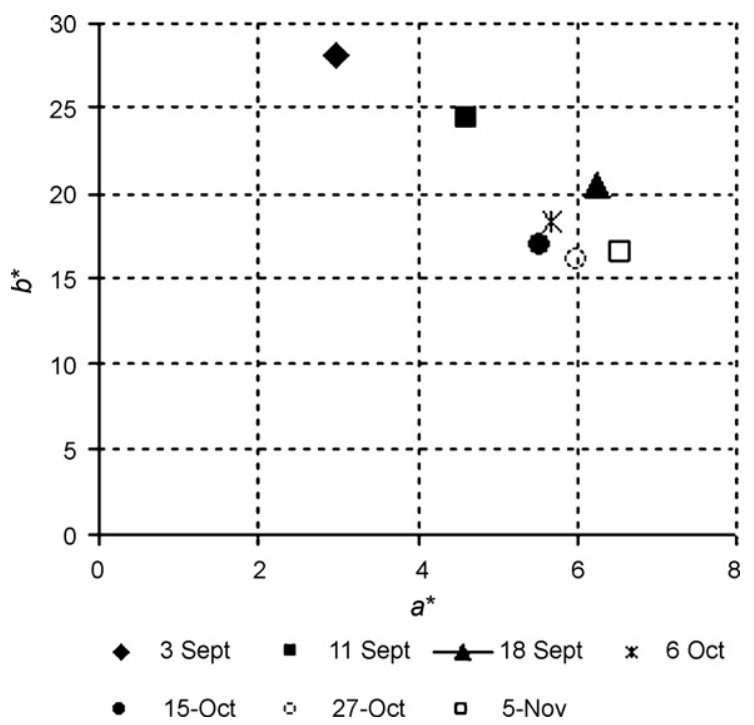

Fig. 4. $a^{*}$ and $b^{*}$ CIELab colour parameters of seed samples from grapes picked at different stages of ripeness.

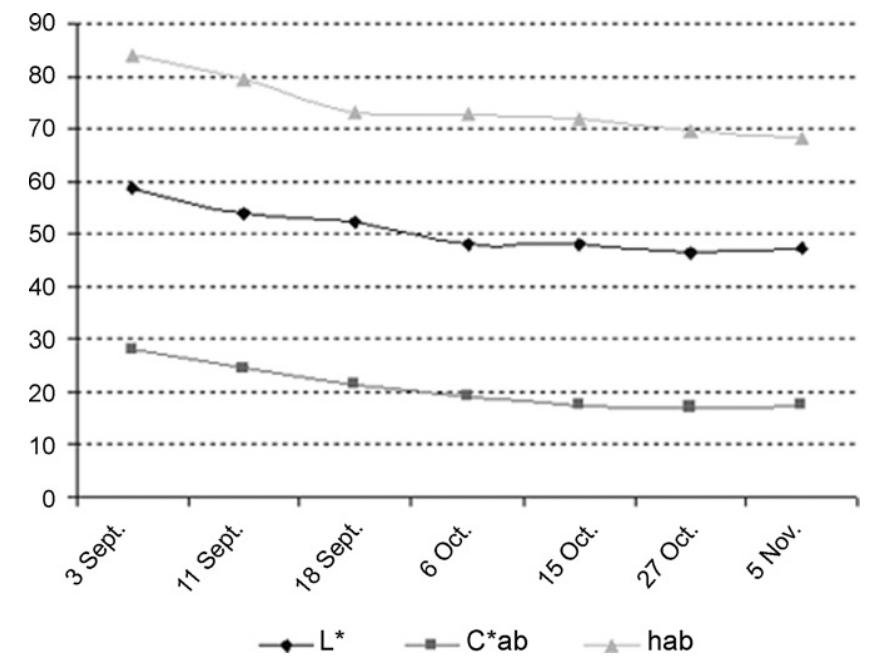

Fig. 5. $C_{a b}^{*}, L^{*}$ and $h_{a b}$ colour parameters of seed samples from grapes picked at different stages of ripeness. 
Table 4

Distribution of flavanolic compounds in the seeds from grapes harvest during 2005-2008.

\begin{tabular}{lcccc}
\hline & \%Total & & \\
\cline { 2 - 5 } & 2005 & 2006 & 2007 & 2008 \\
& Mean \pm S.D. & Mean \pm S.D. & Mean \pm S.D. & Mean \pm S.D. \\
\hline M & $37.72 \pm 1.63^{\mathrm{b}}$ & $27.55 \pm 3.69^{\mathrm{a}}$ & $35.73 \pm 2.81^{\mathrm{b}}$ & $47.29 \pm 0.68^{\mathrm{c}}$ \\
D & $21.42 \pm 0.59^{\mathrm{a}}$ & $24.64 \pm 1.33^{\mathrm{bc}}$ & $25.41 \pm 1.22^{\mathrm{c}}$ & $22.08 \pm 0.48^{\mathrm{ab}}$ \\
DG & $8.63 \pm 0.56^{\mathrm{b}}$ & $9.30 \pm 0.47 \mathrm{~b}^{\mathrm{c}}$ & $6.84 \pm 0.13^{\mathrm{a}}$ & $6.34 \pm 0.39^{\mathrm{a}}$ \\
T & $25.01 \pm 0.85^{\mathrm{b}}$ & $30.30 \pm 2.18^{\mathrm{c}}$ & $25.70 \pm 1.63^{\mathrm{bc}}$ & $19.12 \pm 0.40^{\mathrm{a}}$ \\
TG & $2.32 \pm 0.34^{\mathrm{a}}$ & $3.69 \pm 0.66^{\mathrm{b}}$ & $2.41 \pm 0.09^{\mathrm{a}}$ & $1.28 \pm 0.08^{\mathrm{a}}$ \\
TE & $5.06 \pm 0.76^{\mathrm{a}}$ & $4.53 \pm 0.29^{\mathrm{a}}$ & $3.92 \pm 0.03^{\mathrm{a}}$ & $3.89 \pm 0.33^{\mathrm{a}}$ \\
TTG & $14.68 \pm 0.31^{\mathrm{a}}$ & $16.52 \pm 2.50^{\mathrm{a}}$ & $14.94 \pm 0.16^{\mathrm{a}}$ & $14.32 \pm 0.53^{\mathrm{a}}$ \\
\hline
\end{tabular}

M: monomers; D: dimers; DG: galloylated dimers; T: trimers; TG: galloylated trimers; TE: tetramers; TTG: total galloylated compounds.

S.D. = standard deviation $(n=3)$. Different lower case letters, a, b, c, indicate significant $(p<0.05)$ differences, in the content of the compounds, between samples collected at harvest.

decline of yellow and of green and as a rise of red and blue, giving as a result a brownish colour to the seeds. $C_{a b}^{*}, L^{*}$ and $h_{a b}$, suffer a progressive decrease with time, stabilising from October 15 th (the date after which no modifications in the flavanol profile were observed) (Fig. 5). Colour differences $\left(\Delta E_{a b}^{*}=\left[\left(\Delta L^{*}\right)^{2}+\left(\Delta a^{*}\right)^{2}+\left(\Delta b^{*}\right)^{2}\right]^{1 / 2}\right)$ calculated between the last three samples showed that it was not possible to distinguish the colour between them $\left(\Delta E_{a b}^{*} \leq 1\right)$.

\subsection{Statistical analysis}

Pearson's correlations obtained between the flavanolic composition and sensory parameters showed that the flavanolic compounds which are highly correlated to TI and to A are not the same (Table 5 ). There is a very high correlation between $A$ and galloylated flavanols and especially with galloylated dimers (Pearson's correlations: 0.830 and 0.836 , respectively). Regarding $\mathrm{TI}$, correlations with galloylated flavanols are not as high as in the A parameter, which seems more affected by the presence of galloylation in the molecule.

Multiple linear regression analysis (MLR) was carried out in forward stepwise manner to select suitable variables in the model and only the variables showing significant correlations $(p<0.05)$ in the previous univariate analysis were included in the study. In order to determine which flavanolic compounds or family of flavanolic compounds better explain the variation that occurs in the sensory parameters, the variables A, TI and HS were considered as dependent and the flavanolic compounds as independent variables. The equations thus obtained were as follows:

$\mathrm{HS}=-0.262 \mathrm{DG}+4.022(R=0.877)$

$\mathrm{TI}=0.191 \mathrm{~T}+1.467(R=0.815)$

$\mathrm{A}=0.219 \mathrm{DG}+1.509(R=0.836)$

As can be seen, the best variables to explain the variation that occurs in HS and A were the galloylated dimers and for TI the trimers.

In Table 6 Pearson's correlation coefficients between colorimetric parameters and flavanolic composition of the seed are shown. In accordance with the opposite tendencies observed for the $a^{*}$ and $b^{*}$ parameters, when a flavanolic compound correlates with both (the cases of C, B1, B3, ECG, B2G, M and DG), we find negative and direct correlations, respectively. Once again, galloylated flavanols exhibit the highest correlation coefficients. Epicatechin3-O-gallate has the highest correlations with -0.749 and 0.979 Pearson correlation values for $a^{*}$ and $b^{*}$, respectively. We should not forget that ECG undergoes the most important and sharpest

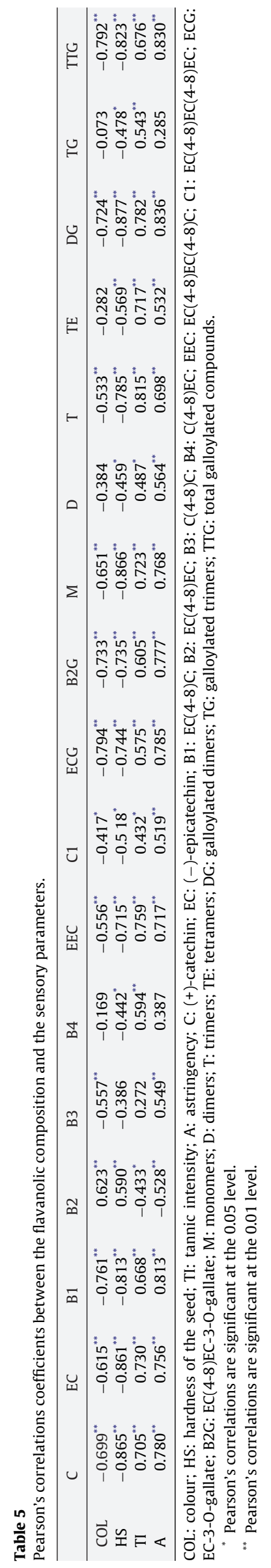


Table 6

Pearson's correlation coefficients between colorimetric parameters and flavanolic composition of the seeds.

\begin{tabular}{|c|c|c|c|c|c|}
\hline & $a^{*}$ & $b^{*}$ & $L^{*}$ & $C_{a b}^{*}$ & $h_{a b}$ \\
\hline C & $-0.464^{*}$ & $0.900^{* *}$ & $0.904^{* *}$ & $0.918^{* *}$ & $0.692^{* *}$ \\
\hline EC & -0.361 & $0.826^{* *}$ & $0.836^{* *}$ & $0.848^{* *}$ & $0.606^{* *}$ \\
\hline B1 & $-0.584^{* *}$ & $0.927^{* *}$ & $0.931^{* *}$ & $0.937^{* *}$ & $0.765^{* *}$ \\
\hline B2 & 0.374 & $-0.678^{* *}$ & $-0.695^{* *}$ & -0.695 & $-0.516^{* *}$ \\
\hline B3 & $-0.818^{* *}$ & $0.790^{* *}$ & $0.764^{* *}$ & $0.760^{* *}$ & $0.851^{* *}$ \\
\hline B4 & 0.276 & 0.107 & 0.130 & 0.143 & -0.091 \\
\hline EEC & -0.179 & $0.621^{* *}$ & $0.621^{* *}$ & $0.652^{* *}$ & 0.402 \\
\hline $\mathrm{C} 1$ & -0.216 & $0.456^{*}$ & $0.459^{*}$ & $0.475^{*}$ & 0.321 \\
\hline ECG & $-0.749^{* *}$ & $0.979^{* *}$ & $0.978^{* *}$ & $0.972^{* *}$ & $0.888^{* *}$ \\
\hline B2G & $-0.673^{* *}$ & $0.907^{* *}$ & $0.917^{* *}$ & $0.899^{* *}$ & $0.819^{* *}$ \\
\hline $\mathrm{M}$ & $-0.404^{*}$ & $0.859^{* *}$ & $0.867^{* *}$ & $0.879^{* *}$ & $0.643^{* *}$ \\
\hline D & -0.395 & $0.537^{* *}$ & $0.530^{* *}$ & $0.531^{* *}$ & $0.501^{*}$ \\
\hline $\mathrm{T}$ & 0.007 & $0.530^{* *}$ & $0.550^{* *}$ & $0.577^{* *}$ & 0.242 \\
\hline $\mathrm{TE}$ & 0.211 & 0.228 & 0.255 & 0.269 & -0.003 \\
\hline DG & $-0.419^{*}$ & $0.843^{* *}$ & $0.866^{* *}$ & $0.862^{* *}$ & $0.640^{* *}$ \\
\hline TG & $0.488^{*}$ & -0.037 & 0.023 & 0.015 & -0.296 \\
\hline TTG & $-0.638^{* *}$ & $0.955^{* *}$ & $0.964^{* *}$ & $0.958^{* *}$ & $0.815^{* *}$ \\
\hline
\end{tabular}

Abbreviations are the same as in Table 5.

* Pearson's correlations are significant at the 0.05 level.

** Pearson's correlations are significant at the 0.01 level.

drop in its concentration during maturation (see Fig. 3). $C_{a b}^{*}, L^{*}$ and $h_{a b}$ have high correlation coefficients with many flavanolic compounds and mainly with ECG, TTG, B2G, B1, C, B3, DG and EC. It is worth emphasising that the flavanol contents of the wines have been found to be correlated with the degree of browning [51] and it is known that the compounds formed from the oxidation of the flavanols during fermentation are responsible for the colour of black tea [52]. The relation we have found between the flavanols (noncoloured flavonoids) could be related, therefore, to these kinds of processes.

The equations obtained from the stepwise multiple regression analysis are listed below. The $\beta$ parameter (standardised regression coefficient) was also obtained in order to achieve a better estimation of the contribution of each variable to the model.

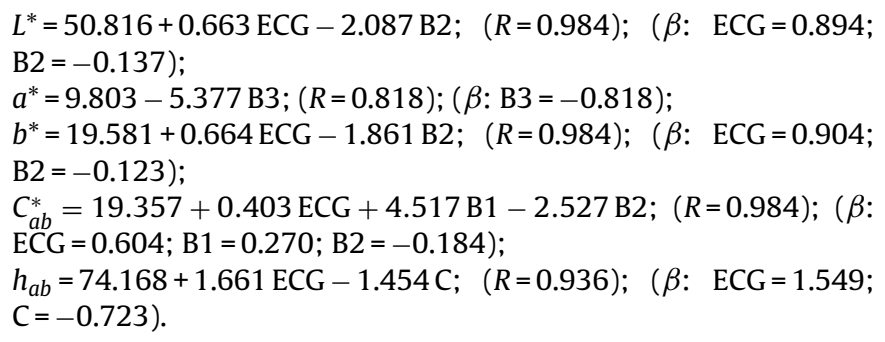

The results show that ECG was the compound most related to the colour parameters such as $L^{*}, b^{*}, C_{a b}^{*}$ and $h_{a b}$, since it showed the highest $\beta$ values. Only in the case of $a^{*}$, did B3 play an important role.

\section{Conclusions}

Grape seeds undergo an important decrease in the content of catechins and procyanidin oligomers during ripening, the content at harvest being approximately a half of that at veraison. B2G and ECG are the flavanolic compounds whose contents decrease the most. Changes in the phenolic composition accompany changes in tannic intensity and astringency which tend to diminish as the maturity degree increases while hardness of the seed shows a contrary trend. When seeds are easily smashed, the dryness and asperity felt on the lips and palate are reduced. Nevertheless, the total content of flavanols in the seed is not the only factor affecting these attributes, since samples containing higher contents in flavanols can exhibit less astringency and tannic intensity than oth- ers with lower ones. Therefore, the qualitative profile of the seeds is also responsible for the sensations elicited in mouth. A and HS parameters are more affected by the presence of galloylation in the molecule than TI.

CIELab colour parameters of seeds have high correlation coefficients with many flavanolic compounds. ECG was the compound most related to the aforementioned parameters. Taking into account that flavanols are non-coloured flavonoids, this relationship could be linked to oxidative processes.

On the other hand, statistical analysis has shown which compounds were the most related with sensorial and colour parameters. This could be use in order to elucidate sensorial and colour attributes from them. Nevertheless, a more comprehensive study is necessary to predict sensorial and colour attributes from flavanolic compounds and vice versa which would help to take decisions during the harvest.

\section{Acknowledgements}

Thanks are due to the Spanish MICINN and FEDER for financial support (Project ref. AGL2008-05569-C02-01) and for to an F.P.U. predoctoral scholarship to R. Ferrer-Gallego. The authors also thank Bodegas RODA S.A. (Haro, La Rioja, Spain) for supplying the grape samples and Mr. G.H. Jenkins for his help with the English version of the ms.

\section{References}

[1] J.J. Macheix, A. Fleuriet, J. Billot, Fruit Phenolic, CRC Press, Inc., Boca Raton, FL, USA, 1990, p. 378.

[2] V. Núñez, C. Gómez-Cordovés, B. Bartolomé, Y.J. Hong, A.E. Mitchell, J. Sci. Food Agric. 86 (2006) 915.

[3] R. Rodríguez-Montealegre, R. Romero Peces, J.L. Chacón-Vozmediano, J. Martínez, E. Gascueña, E. García-Romero, J. Food Compos. Anal. 9 (2006) 687.

[4] J.A. Kennedy, G.J. Troup, J.R. Pilbrow, D.R. Hutton, D. Hewitt, C.A. Hunter, R. Ristic, P.G. Iland, G.P. Jones, Aust. J. Grape Wine Res. 6 (2000) 244.

[5] J.A. Kennedy, Y. Hayasaka, S. Vidal, E.J. Waters, G.P. Jones, J. Agric. Food Chem. 49 (2001) 5348.

[6] J. Osmianski, J.C. Sapis, J. Agric. Food Chem. 37 (1989) 1293.

[7] M.C. Dumond, J. Michaud, J. Masquelier, Bull. OIV 64 (1991) 533.

[8] R. Ristic, P.G. Iland, Aust. J. Grape Wine Res. 11 (2005) 43.

[9] F.M. Romeyer, J. Macheix, J.C. Sapis, Phytochemistry 25 (1986) 219.

[10] V.A.P. de Freitas, Y. Glories, A. Monique, Am. J. Enol. Vitic. 51 (2000) 397.

[11] J.A. Kennedy, M.A. Matthews, A.L. Waterhouse, Phytochemistry 55 (2000) 77.

[12] Y. Cadot, M.T. Miñana-Castelló, M. Chevalier, J. Agric. Food Chem. 54 (2006) 9206.

[13] M. Bourzeix, D. Weyland, N. Heredia, Bull. OIV 59 (1986) 1171.

[14] J.M. Ricardo da Silva, J. Rigaud, V. Cheynier, A. Cheminat, M. Moutounet, Phytochemistry 30 (1991) 1259. 
[15] J.M. Ricardo da Silva, J.P. Rosec, M. Bourzeix, J. Mourgues, M. Moutonet, Vitis 31 (1992) 55.

[16] B.S. Sun, T. Pinto, M.C. Leandro, J.M. Ricardo-da-Silva, M.I. Spranger, Am. J. Enol Vitic. 50 (1999) 179.

[17] A.M. Jordao, J.M. Ricardo-da-Silva, O. Laureano, Vitis 37 (1998) 93.

[18] A.M. Jordao, J.M. Ricardo da Silva, O. Laureano, Am. J. Enol. Vitic. 52 (2001) 230

[19] T. Fuleki, J.M. Ricardo da Silva, J. Agric. Food Chem. 45 (1997) 1156.

[20] C. Santos-Buelga, S. Bravo-Haro, J.C. Rivas-Gonzalo, Z. Lebnsm. Unters. Forsch. A 201 (1995) 269.

[21] V.A.P. de Freitas, Y. Glories, G. Bourgeois, C. Vitry, Phytochemistry 49 (1998) 1435.

[22] M.T. Escribano-Bailon, M.T. Guerra, J.C. Rivas-Gonzalo, C. Santos-Buelga, Z. Lebnsm. Unters. Forsch. A 200 (1995) 221.

[23] E. Bate-Smith, Food Process. Pack 23 (1954) 124

[24] C.B. Lee, H.T. Lawless, Chem. Senses 16 (1991) 225.

[25] P.A.S. Breslin, M.M. Gilmore, G.K. Beachamp, B.G. Gren, Chem. Senses 18 (1993) 405.

[26] G. Ares, C. Barreiro, R. Deliza, A. Gámbaro, Food Res. Int. 42 (2009) 871

[27] O.M. Andersen, Flavonoids, in: O.M. Andersen, K.R. Markham (Eds.), Chemistry, Biochemistry and Applications. Editorial, Taylor \& Francis Group, London, 2006.

[28] E. Haslam, J. Chem. Soc., Chem. Commun. (1981) 309.

[29] T. Okuda, K. Mori, T. Hatano, Chem. Pharm. Bull. 33 (1985) 1424.

[30] L.J. Porter, J. Woodruffe, Phytochemistry 23 (1984) 1255.

[31] J.M. Ricardo da Silva, V. Cheynier, J.M. Souquet, M. Moutounet, J.C. Cabanis, M. Bourzeix, J. Sci. Food Agric. 57 (1991) 111.

[32] P. Sarni-Machado, V. Cheynier, M. Moutounet, J. Agric. Food Chem. 47 (1999) 42.

[33] C. Maury, P. Sarni-Machado, S. Lefebvre, V. Cheynier, M. Moutounet, Am. J. Enol. Vitic. 52 (2001) 140.
[34] E.C. Bate-Smith, Phytochemistry 12 (1973) 907.

35] Z. Czochanska, L.Y. Foo, L.J. Porter, Phytochemistry 18 (1979) 1819

[36] Y. Glories, Connaisance Vigne Vin 18 (1984) 195.

37] V. Freitas, N. Mateus, J. Agric. Food Chem. 49 (2001) 940.

[38] M.C. Llaudí, R. Canals, J.M. Canals, N. Rozés, L. Arola, F. Zamora, J. Agric. Food Chem. 52 (2004) 742.

[39] E. Monteleone, N. Condelli, C. Dinnela, M. Bertuccioli, Food Qual. Prefer. 15 (2004) 761.

40] G. Fia, C. Dinnella, M. Bertuccioli, E. Monteleone, Food Chem. 113 (2009) 325.

[41] N. Hayashi, R. Chen, H. Ikezaki, S. Yamaguchi, D. Maruyama, Y. Yamaguchi, T. Ujihara, K. Kohata, Biosci. Biotechnol. Biochem. 70 (2006) 626.

[42] J. Rousseau, D. Delteil, Revue Française d'Oenologie 183 (2000) 10

[43] L. Martinez, Revue des Oenologues 105 (2002) 19.

[44] M. Le Moigne, R. Symoneaux, F. Jourjon, Food Qual. Prefer. 19 (2008) 672.

[45] M. García-Marino, J.C. Rivas-Gonzalo, E. Ibáñez, C. García-Moreno, Anal. Chim. Acta 563 (2006) 44

[46] S. González-Manzano, C. Santos-Buelga, J.J. Pérez-Alonso, J.C. Rivas-Gonzalo M.T. Escribano-Bailón, J. Agric. Food Chem. 54 (2006) 4326.

[47] S. Pascual-Teresa, J.C. Rivas-Gonzalo, C. Santos-Buelga, Int. J. Food Sci. Technol. 35 (2000) 33

[48] M.T. Escribano-Bailon, Y. Gutierrez-Fernandez, J.C. Rivas-Gonzalo, C. SantosBuelga, J. Agric. Food Chem. 40 (1992) 1794.

[49] A.G.H. Lea, in: R.L. Rouseff(Ed.), Developments in Food Science, vol. 25, Elseiver, Amsterdam, 1990, p. 123.

[50] H. Peleg, K. Gacon, P. Schilch, A.C. Noble, J. Sci. Food Agric. 79 (1999) 1123.

[51] P. Fernández-Zurbano, V. Ferreira, A. Escudero, J. Cacho, J. Agric. Food Chem. 46 (1998) 4937.

[52] H.D. Belitz, W. Grosch, P. Schieberle, Food Chemistry, 4th ed., Springer, 2009, p. 1166. 